\title{
Comparative Analysis of Regional Innovative Development Indexes in the Space of Expert- Defined Characteristics of Regional Differentiation
}

\author{
Maria Lysenkova*, and Mikhail Afanasiev \\ Russian Academy of Sciences, 117418 Moscow, Russia
}

\begin{abstract}
The purpose of the study is to compare the indexes of innovative development of regions and identify indexes that do not have significant differences. In this article, we used an approach that allows comparing an arbitrary set of indexes of innovative development of the Russian Federation regions in the space of differentiation characteristics used in solving project management problems. Eight indexes are compared: four author's indexes constructed using estimates of the technical efficiency of interaction between science and business in the region and four published indexes with a similar applied focus. Comparative analysis of indices is carried out in the space of expertdefined characteristics of regional differentiation. An approach has been tested to identify indexes that are not distinguishable when solving control problems parameterized using differentiation characteristics.
\end{abstract}

\section{Introduction}

Currently, a lot of indexes are published that characterize various aspects of innovative development of regions. As a rule, the source information and methods used for their construction have specifics that allow the authors to consider these indexes as original and recommend them for use in solving a number of management problems. However, a comparative analysis of such indexes sometimes shows that, despite the peculiar names and methods of calculation, some of them do not have significant statistical differences. In this paper, we use an approach that allows us to compare an arbitrary set of indices of innovative development of the subjects of the Russian Federation in the space of differentiation characteristics used in solving project management problems. Issues related to the formation of the space of such characteristics in the context of solving project management problems are considered by the authors in their works $[1,2]$. Here we use one of the possible sets of differentiation characteristics, the quality of which was evaluated in the works $[3,4]$.

${ }^{*}$ Corresponding author: 1ysenkovam@gmail.com 
The paper uses the basis $\left.B_{t}^{\square}=\left\{l_{k, t}, s_{k, t}^{1}, s_{k, t}^{2}, t e_{k, t}, d t e_{k, t}\right)\right\}_{k}$ of characteristics of regional differentiation at a time $t$ includes five components: $l_{k, t}$ - the scale of the region's economy at the moment, $t e_{k, t}$ - a comparable assessment of technical efficiency; $s_{k, t}^{1}-$ index of industry specialization; $s_{k, t}^{2}$ - the index of industrialization; $d t e_{k, t}$ - the trend of the technical efficiency. The Federal State Statistic Service (Rosstat) indicator named "number of economically active population" is used As a characteristic of the scale of the economy,. The basis includes the first (index of industry specialization) and second (index of industrialization) main components of the GRP structure. The author's methodology and Rosstat indicators for the industry structure of GRP were used for the constructing of the main components [1].

Based on the concept of a stochastic boundary [5], using these production functions, estimates of the technical efficiency of the regions of each group are obtained. A method is proposed that allows us to bring technical efficiency estimates to a comparable form for all regions [6]. Taking into account the concept of localization, the relative inefficiency of the region in the group of homogeneity is due to the fact that it does not fully use the available development opportunities. Therefore, an assessment of technical efficiency that is comparable across all regions and an assessment of the technical efficiency trend are considered as characteristics of management quality.

\section{Method and Materials for Comparison of Innovation Development Indexes}

At the first stage of the study, a correlation analysis of indices is performed. If for some index the modules of correlation coefficients with other indices are close to zero, then this index can be excluded from consideration as independent, having a significant difference from others. Correlation analysis allows you to reduce the number of indexes analyzed in the following stages.

At the second stage, regressions of each index are built on the basic characteristics of differentiation. Based on the analysis of beta coefficients, differentiation characteristics are identified that have a significant impact on the indices under consideration.

The paper compares eight indexes their description is presented in the table (Table 1).

Table 1. Innovation activity indexes used in the model

\begin{tabular}{|c|c|c|}
\hline Name & Description & Source \\
\hline \multicolumn{3}{|c|}{ Author's indexes } \\
\hline $\begin{array}{l}\text { Index of technical } \\
\text { efficiency of the } \\
\text { innovation space for } \\
\text { international patent } \\
\text { applications TEMPZ }\end{array}$ & $\begin{array}{l}\text { The index is an assessment of the technical efficiency } \\
\text { of the innovation space for a total of } 80 \text { regions of the } \\
\text { Russian Federation when creating international patent } \\
\text { applications, obtained using a model of the type } \\
\text { M1: } \ln \boldsymbol{Q}_{\boldsymbol{i}}=\boldsymbol{c}+\boldsymbol{\delta} \ln \boldsymbol{V}_{\boldsymbol{i}}+\boldsymbol{v}_{\boldsymbol{i}}-\boldsymbol{u}_{\boldsymbol{i}}, \\
\text { estimated for the regions of the Russian Federation }\end{array}$ & $\begin{array}{l}\text { The author's index is } \\
\text { published in }[7,8]\end{array}$ \\
\hline $\begin{array}{l}\text { Index of technical } \\
\text { efficiency of the } \\
\text { innovation space for } \\
\text { patent applications } \\
\text { TEPZ }\end{array}$ & $\begin{array}{l}\text { The index represents estimates of the technical } \\
\text { efficiency of the innovation space for a total of } 80 \\
\text { regions of the Russian Federation when creating patent } \\
\text { applications, obtained using the M1 model evaluated } \\
\text { for the regions of the Russian Federation }\end{array}$ & $\begin{array}{l}\text { The author's index is } \\
\text { published in }[7,8]\end{array}$ \\
\hline $\begin{array}{l}\text { Index of technical } \\
\text { efficiency of the } \\
\text { innovation space by } \\
\text { issued patents TEPV }\end{array}$ & $\begin{array}{l}\text { The index represents estimates of the technical } \\
\text { efficiency of the innovation space for a total of } 80 \\
\text { regions of the Russian Federation when creating issued } \\
\text { patents, obtained using the M1 model evaluated for the } \\
\text { regions of the Russian Federation }\end{array}$ & $\begin{array}{c}\text { The author's index is } \\
\text { published in [9] }\end{array}$ \\
\hline
\end{tabular}


Table 1. Continued

\begin{tabular}{|c|c|c|}
\hline $\begin{array}{l}\text { Index of technical } \\
\text { efficiency of the } \\
\text { innovation space based } \\
\text { on the developed new } \\
\text { technologies TETECH }\end{array}$ & $\begin{array}{l}\text { The index represents estimates of the technical } \\
\text { efficiency of the innovation space for a total of } 80 \\
\text { regions of the Russian Federation when creating new } \\
\text { production technologies, obtained using the M1 model } \\
\text { evaluated for the regions of the Russian Federation. }\end{array}$ & The author's index \\
\hline \multicolumn{3}{|c|}{ Indexes with the similar application focus } \\
\hline $\begin{array}{l}\text { The rating of index of } \\
\text { regional innovation } \\
\text { INN1 }\end{array}$ & $\begin{array}{c}\text { The rating is based on an original system of } \\
\text { quantitative and qualitative indicators of innovative } \\
\text { development of regions, which is based on the results } \\
\text { of long-term research of the High School of Economics } \\
\text { University }\end{array}$ & [10] \\
\hline $\begin{array}{l}\text { The rating of scientific- } \\
\text { technical potential INN2 }\end{array}$ & $\begin{array}{l}\text { The rating of regions of the Russian Federation, formed } \\
\text { on the basis of the index of scientific and technical } \\
\text { potential, is a composite assessment that reflects the } \\
\text { development of scientific and technical potential of } \\
\text { regions in such components as human and financial } \\
\text { resources for research and development, publication } \\
\text { and patent activity, development of advanced } \\
\text { production technologies and export of technological } \\
\text { services. }\end{array}$ & {$[10]$} \\
\hline $\begin{array}{l}\text { Index of science and } \\
\text { technology development } \\
\text { in the regions of Russia } \\
\text { INN3 }\end{array}$ & $\begin{array}{l}\text { The positions of Russian regions in the final list were } \\
\text { determined on the basis of an integral index, which was } \\
\text { calculated by aggregating the rating points of regions } \\
\text { for } 19 \text { analyzed indicators, grouped into } 4 \text { groups:" } \\
\text { Human resources"," Material and technical base"," } \\
\text { Efficiency of scientific and technological activities } \\
\text { "and"Scale of scientific and technological activities". }\end{array}$ & [11] \\
\hline $\begin{array}{l}\text { Rating of innovative } \\
\text { regions for the purpose } \\
\text { of monitoring and } \\
\text { management INN4 }\end{array}$ & $\begin{array}{l}\text { The rating of innovative regions for monitoring and } \\
\text { management purposes was developed by the } \\
\text { Association of innovative regions of Russia in } 2012 \\
\text { together with the Ministry of economic development of } \\
\text { the Russian Federation, with the participation of } \\
\text { representatives of regional administrations and leading } \\
\text { experts of the country. }\end{array}$ & [12] \\
\hline
\end{tabular}

\section{Analysis of the Main Results of the Comparison of Innovation Development Indexes}

The table (Table 2) shows the results of the correlation analysis of indices conducted at the first stage of the research.

Table 2. Index correlation coefficients

\begin{tabular}{|l|l|l|l|l|l|l|l|l|}
\hline & TEMPZ & TEPZ & TEPV & TETECH & INN1 & INN2 & INN3 & INN4 \\
\hline TEMPZ & 1 & & & & & & & \\
\hline TEPZ & 0.047 & 1 & & & & & & \\
\hline TEPV & 0.067 & 0.873 & 1 & & & & & \\
\hline TETECH & 0.405 & 0.158 & 0.136 & 1 & & & & \\
\hline INN1 & 0.371 & 0.274 & 0.321 & 0.354 & 1 & & & \\
\hline INN2 & $\mathbf{0 . 4 1 6}$ & 0.228 & 0.251 & 0.286 & 0.765 & 1 & & \\
\hline INN3 & $\mathbf{0 . 3 7 4}$ & 0.261 & 0.275 & 0.275 & 0.928 & 0.769 & 1 & \\
\hline INN4 & $\mathbf{0 . 2 9 4}$ & 0.178 & 0.218 & 0.149 & 0.852 & 0.701 & 0.846 & 1 \\
\hline
\end{tabular}

The author's indexes based on Rosstat data on patent applications TEPZ and issued TEPV patents are correlated with a coefficient of 0.874 . This is natural, since for each region the number of patents granted is determined by the number of applications submitted. 
The TEMPZ index based on data on international patent applications is not correlated with the TEPZ and TEPV indexes based on data on patent applications and patents issued in Russia. This can be explained by the fact that international patent applications that provide legal protection of inventions outside the territory of the Russian Federation are usually filed for more significant inventions than some domestic patent applications. The TEMPZ index is closer in structure to the tech index, based on data on new production technologies developed in Russia. There is a significant correlation between them.

The author's indexes are practically not correlated with other indexes under consideration.

The table (Table 3) shows the regressions of each index on the basic characteristics of differentiation.

Table 3. Regression of indexes on differentiation characteristics

\begin{tabular}{|c|c|c|c|c|c|c|}
\hline & $\mathbf{R}^{2}$ & 1 & te & s1 & s2 & dte \\
\hline \multirow[t]{2}{*}{ TEMPZ } & 0,344 & 0,125 & 0,067 & $-0,323$ & 0,350 & 0,130 \\
\hline & $P>t$ & 0,242 & 0,539 & $\mathbf{0 , 0 0 7}$ & 0,001 & 0,204 \\
\hline \multirow[t]{2}{*}{ TEPV } & 0,229 & 0,071 & $-0,202$ & $-0,304$ & 0,193 & $-0,215$ \\
\hline & $\mathbf{P}>\mathbf{t}$ & 0,509 & 0,069 & 0,005 & 0,075 & $\mathbf{0 , 0 3 9}$ \\
\hline \multirow[t]{2}{*}{ TEPZ } & 0,167 & 0,195 & $-0,209$ & $-0,239$ & 0,073 & $-0,081$ \\
\hline & $P>t$ & 0,083 & 0,070 & $\mathbf{0 , 0 3 3}$ & 0,516 & 0,453 \\
\hline \multirow[t]{2}{*}{ TETECH } & 0,108 & 0,086 & 0,206 & $-0,093$ & 0,091 & 0,180 \\
\hline & $P>t$ & 0,459 & 0,085 & 0,419 & 0,430 & 0,108 \\
\hline \multirow[t]{2}{*}{ INN1 } & 0,518 & 0,486 & 0,096 & $-0,106$ & 0,359 & 0,145 \\
\hline & $\mathbf{P}>\mathbf{t}$ & 0,000 & 0,273 & 0,208 & 0,000 & 0,078 \\
\hline \multirow[t]{2}{*}{ INN2 } & 0,491 & 0,500 & 0,014 & $-0,001$ & 0,389 & 0,081 \\
\hline & $P>t$ & 0,000 & 0,874 & 0,989 & 0,000 & 0,332 \\
\hline \multirow[t]{2}{*}{ INN3 } & 0,723 & 0,588 & 0,077 & $-0,078$ & 0,452 & 0,117 \\
\hline & $P>t$ & 0,000 & 0,246 & 0,226 & 0,000 & 0,061 \\
\hline \multirow[t]{2}{*}{ INN4 } & 0,632 & 0,528 & 0,077 & $-0,174$ & 0,414 & 0,103 \\
\hline & $P>t$ & 0,000 & 0,309 & $\mathbf{0 , 0 2 0}$ & 0,000 & 0,150 \\
\hline
\end{tabular}

The table (Table 3 ) shows that the index INN1 has only two significant ratings among all 5 ratings for $l$, te, $s 1$, etc. Only two ratings for $l$ and $s 2$ are considered different from 0 . This means that all external indexes are arranged the same, with the exception of the last index INN4, take into account the scale of the economy and the 2nd main component of the GRP structure that distinguishes the processing regions. This means that a region with a large economy creates more results of innovation activity or that manufacturing regions are more innovative than others, which is obvious, since these regions are usually home to advanced technologies.

The author's indexes show a different picture. They also have few significant components. Both the first and second components are significant in the TEMPZ index. But $s 2$ is already taken into account by other indexes, and the author's three indexes take into account the first main component, which is of practical interest. The main originality of the author's indexes is that they do not take into account the scale of the economy and evaluate innovation activity regardless of the scale of the economy. Thus, this table shows that all INN1-INN4 indexes are arranged almost identically, while the author's indexes are arranged differently.

\section{Conclusions}

1. Correlation analysis of indices that characterize the innovative development of regions shows that the group of indices inn1, inn2, inn3, inn4 has a similar applied orientation. At 
the same time, the author's indexes of technical efficiency of the innovation space are specific in relation to other indexes of innovative development.

2. Analysis of the beta coefficients of the indexes on the characteristics of regional differentiation shows that the strongest influence on the indices of the economy's size, the first main component of the structure of GRP, which separates the upstream (highest value) and other regions, and the second main component of the structure of GRP, which parts machining (maximum value), evenly developed, agricultural, and developing (the lowest value) regions. The technical efficiency of regional production and the trend of technical efficiency practically do not affect the indices of innovative development.

\section{Acknowledgements}

The article has been prepared as a part of the public task of the Central Economics and Mathematics Institute of Russian Academy of Sciences.

\section{References}

1. S. A. Aivazian, M. Yu. Afanasiev, A. V. Kudrov, Applied Econometrics, 41, 24 (2016)

2. M. Yu. Afanasiev, S. A. Aivazian, A. V. Kudrov, Economics and the Mathematical Methods, 52.1, 28 (2016)

3. M. Yu. Afanasiev, S. A. Aivazian, A. V. Kudrov, Economics and the Mathematical Methods, 54(1), 43 (2018)

4. S. A. Aivazian, M. Yu. Afanasiev, A. V. Kudrov, Applied Econometrics, 54, 51 (2019)

5. S. Kumbhakar, K. Lovell, Stochastic frontier analysis (Cambridge University Press, 2004).

6. S. A. Aivazian, M. Yu. Afanasiev, A. V. Kudrov, Montenegrin J. of Economics, 14(3), 7 (2018)

7. S. A. Aivazian, M. Yu. Afanasiev, A. V. Kudrov, M.A. Lysenkova, Applied Econometrics, 45, 29 (2017)

8. S. A. Aivazian, M. Yu. Afanasiev, A. V. Kudrov, Montenegrin Journal of Economics, 13(2), 7 (2017)

9. S. A. Aivazian, M. Yu. Afanasiev, Lysenkova, Mathematics, Computer, Education, 23(4), 94 (2016)

10. G. Abdrakhmanova, P. Bakhtin, L. Gokhberg, Russian Regional Innovation Scoreboard, 5, (2017)

11. RIA Rating, https://riarating.ru/

12. Prospect development of innovative economy: materials of the I international research and practice conference April 30th, Los Gatos (CA), 78 (2016) 